\title{
Estimate of Global Solar Radiation Using Artificial Neural Network Based on Meteorological Parameters in Yola
}

\author{
*Ogbaka D.T, \\ Department of \\ Pure and Applied \\ Physics, Faculty of \\ Science. Adamawa \\ State University, \\ Mubi. Adamawa \\ State, Nigeria.
}

\author{
Abdullahi G., \\ Department of \\ Electrical and \\ Electronic, School \\ of Engineering and \\ Engineering \\ Technology, \\ Federal \\ Polytechnic, Mubi,
}

\author{
Adamawa State, \\ Nigeria. \\ Augustine B., \\ Department of \\ Pure and Applied \\ Physics, Faculty of \\ Science. Adamawa \\ State University, \\ Mubi. Adamawa \\ State, Nigeria.
}

Tashara S.

Department of

Computer Science,

Modibbo Adama

University of

Technology Yola,

Adamawa State

Nigeria.

\begin{abstract}
Artificial neural networks have been used widely in many application areas. Artificial Neural Networks (ANNs) are currently accepted as an alternative technology offering a way to tackle complex and illdefined problems. Despite the great importance of Global Solar Radiation (GSR), the number of radiation stations are very less when compared to the stations that collect regular meteorological data like air temperature and humidity. The main objective of this paper is to study the feasibility of an Artificial Neural Network (ANN) based method to estimate and predict GSR based on metrological parameters. It is very encouraging to observe a very close agreement between the ANN and the measured values. The Root Mean Square Error values, which are is the measure of accuracy of a particular model or correlation use. For the present analysis, it was found to be lowest for ANN model value (4.74). The Mean Bias Error value has the lowest under estimation with a value of -1.029, which fall within the expected and acceptable range A low value of MPE is expected, ANN model was observed to have a Mean Percentage Error value of (- 2.345). The result of this study proves that ANN can be used to predict global solar radiation potential in Yola, Nigeria using meteorological data.
\end{abstract}

Keywords: Artificial Neural Networks, Back Propagation, Global Solar Radiation, Meteorological

\section{INTRODUCTION}

For the improvement of quality of life of human being as well as economic and social development, energy is an essential factor. Solar energy reaches to the earth for the every year is 160 times the world's proven fossil fuel reserves, it is expected that the recent worldwide research and development on solar energy will help to reduce the energy crisis of the world (Kartini et al., 2015; Medugu et al., 2013). Solar radiation data are a fundamental input for solar energy utilization such as photovoltaic and solar thermal system design. For optimization and performance evaluation of solar technology for any particular location, the solar radiation data should be easily and readily available (Gana et al., 2014). Solar radiation at the earth's surface is essential for the development and utilization of solar energy. It is needed for designing collectors for solar heaters and other photovoltaic equipment that depend on solar energy. Incoming solar radiation has a significant role in hydrological and crop growth modelling. For instance, it is a key input for estimating potential evapotranspiration which play a major role in the design of water supply storage reservoirs and irrigation systems. In spite of the importance of 
global solar radiation data, its measurements are not frequently available especially in developing countries (Allen, 1997).

An accurate knowledge of solar radiation distribution at a particular geographical location is of vital importance for the development of many solar energy devices. Unfortunately, for many developing countries solar radiation measurements are not easily available due to the shortage of measurement equipment's (Okundamiya and Nzeako, 2010). It is therefore important to consider methods of estimating the solar radiation using Artificial neural networks on the readily available meteorological parameters.

Artificial neural networks have applications in various fields of aerospace, defence, automotive, mathematics, engineering, medicine, economics, meteorology, psychology, neurology, and many others. They have also been used in weather and market trends forecasting, in the prediction of mineral exploration sites, in electrical and thermal load prediction, in adaptive and robotic control and many others2. Neural networks are used for process control because they can build predictive models of the process from multidimensional data routinely collected from sensors. Several researchers have demonstrated that they can be more reliable at predicting energy consumption in a building than other traditional statistical approach because of their ability to model non-linear patterns (Anstett and Kreider, 1992; Stevenson, 1994).

Artificial neural networks are composed of simple elements operating in parallel. The most popular learning algorithms are the backpropagation and its variants5. The BackPropagation (BP) algorithm is one of the most powerful learning algorithms in neural networks. It tries to improve the performance of the neural network by reducing the total error by changing the weights along its gradient. The training of all patterns of a training data set is called an epoch. The training set has to be a representative collection of input-output examples.

When building the neural network model the process has to be identified with respect to the input and output variables that characterise the process. The inputs include measurements of the physical dimensions, measurements of the variables specific to the environment and equipment and controlled variables modified by the operator. Three types of networks used most commonly in ANN applications are feed forward networks, competitive networks and recurrent associative memory networks. A practical description of ANN methods with sample applications was presented in Hagan, Demuth and Beale (1997).

Many of the building energy systems are exactly the types of problems and issues for which the artificial neural network (ANN) approach appear to be most applicable. Neural networks have the potential for making better, quicker and more practical predictions than any of the traditional methods. The performance of a building energy system depends on the environmental conditions such as solar radiation and wind speed, the direction, strength and duration of which are highly variable. Many of the building energy systems are exactly the types of problems and issues for which the artificial neural network (ANN) approach appear to be most applicable. In these computational models attempts are made to simulate the powerful cognitive and sensory functions of the human brain and to use this capability to represent and manipulate knowledge in the form of patterns. Based on these patterns neural networks model input- output functional relationships and can make predictions about other combinations of unseen inputs. Neural networks 
have the potential for making better, quicker and more practical predictions than any of the traditional methods (Kreider and Wan, 1991).

\section{MATERIALS AND METHOD}

Yola, the capital of Adamawa State, comprising of Yola North and Yola South Local Government Areas, is located between Longitudes $12^{\circ} 12^{\prime} \mathrm{E}, 12^{\circ} 33^{\prime} \mathrm{E}$ of the Prime Meridian and between Latitudes $09^{\circ} 12^{\prime} \mathrm{N}, 09^{\circ} 19^{\prime} \mathrm{N}$ of the Equator. It is situated in the Benue Valley area of the state with a mean elevation 186 m.a.s.l. The area falls within the Tropical Wet and Dry/ West African Savanna Climate zone of Nigeria, with pronounced dry season in the low-sun months and wet season in the high-sun months. It is characterized by an average range of sunshine hours of 5.5 hours per day in August to 9.7 hours per day from the months of January through March. On balance, there are 2,954 sunshine hours annually and approximately 8.1 sunlight hours per day. Its Temperature characteristic is high all year round due to high solar radiation effect. However, seasonal changes usually occur such that there is a gradual increase in temperature from January to April when the seasonal maxima is recorded. Then a distinct gradual decline is recorded from the onset of rains in April/May due to cloud effects. This temperature characteristic continuous until October when a slight increase is experienced at the cessation of rains before the arrival of cold dry continental winds (harmattan) conditions (Adebayo, 1999). Thus, the study area is characterized by a mean temperature of $27.9{ }^{\circ} \mathrm{C}$ with a mean monthly range of $6.5^{\circ} \mathrm{C}$. The warmest mean maximum/ high temperature of the area is 39 ${ }^{\circ} \mathrm{C}$ in March \& April, while the coolest mean minimum/ low temperature is $16{ }^{\circ} \mathrm{C}$ in December (Yola Climate Report, 2012).
The Angstrom- Prescott regression equation which has been used to estimate the monthly average daily solar radiation on a horizontal surface in Nigeria or other places is given as:

$\frac{H_{m}}{H_{o}}=\left[a+b \frac{s}{s_{o}}\right]$

$H_{m}$ is daily mean values of global radiation $\left(\mathrm{MJm}^{-}\right.$ ${ }^{2}$ day $\left.^{-1}\right), S_{o}$ the daily average value of day length, and ' $a$ ' and ' $b$ ' values are known as Angstrom constants and they are empirical. $\mathrm{H}_{\mathrm{o}}$ is daily mean values of extraterrestrial radiation $\left(\mathrm{MJm}^{-2} \mathrm{day}^{-1}\right)$, calculated using equation (2) as described by Prescott, (1940).

$H_{o}=\frac{24 \times 3,600}{\pi} I_{s c} E_{o}\left[\cos (\varphi) \cos (\delta) \sin \left(\omega_{s}\right)+\right.$

$\left.\frac{\pi \omega_{s}}{180} \sin (\varphi) \sin (\delta)\right]$

$I_{s c}=\frac{1,367 \times 3,600}{1,000,000} \mathrm{MJm}^{-2} \mathrm{day}^{-1}$

$\mathrm{I}_{\mathrm{s}}$ the solar constant, The units in $\mathrm{kWhm}^{-2} \mathrm{day}^{-1}$

$\mathrm{E}_{\mathrm{o}}$ represents the eccentricity correction, and described using Eq. (3.4) in Eq. 3.2

$E_{o}=1+0.033 \cos \frac{360 n_{d}}{365}$

$\mathrm{n}_{\mathrm{d}}$ is the day number of the year /Julian day (1 Jan, $\mathrm{n}_{\mathrm{d}}=1$ and $31^{\mathrm{st}}$ December, $\left.\mathrm{n}_{\mathrm{d}}=365\right), \varphi$ is the latitude of the site, $\delta$ the solar declination and, $\omega_{\mathrm{s}}$, the mean sunset hour angle for the given month. The solar declination $(\delta)$ and the mean sunset hour angle $\left(\omega_{\mathrm{s}}\right)$ can be calculated as suggested by Duffie and Beckman, (1991):

$\delta=23.45 \sin 360 \frac{284+n_{d}}{265}$

$\omega_{s}=\cos ^{-1}(-\tan \varphi \tan \delta)$

For a given day, the maximum possible sunshine duration (monthly values of day length, $\left(S_{o}\right)$ can be computed by using Cooper's formula (1969):

$S_{o}=\frac{2}{15} \cos ^{-1}(-\tan \varphi \tan \delta)$

For a given day, the maximum possible sunshine duration (monthly values of day length, $(\mathrm{N})$ can be computed by using (Duffie and Beckman, 1991):

$N=\frac{2}{15} \omega_{s}$ 
Falayi (2011), developed a model containing relative humidity, rainfall, cloud cover and temperature for Sokoto, which is Model 1.

$\frac{H_{m}}{H_{o}}=-4.03308+0.0740\left(T_{\max }-T_{\min }\right)+$

$0.01075(R H)-0.00065(R F)+9.008(C C)(8)$

He also developed for Maiduguri, considered as Model 2 for this work:

$\frac{H_{m}}{H_{o}}=0.22093+0.02179\left(T_{\max }-T_{\min }\right)+$

$0.21792(R H)-0.7561(R F)-0.0008(C C)(9)$

Bristow and Campbell Model

Bristow and Campbell (1984) developed a simple model for daily global solar radiation with a different structure in which $\mathrm{H}$ is an exponential function of $\Delta \mathrm{T}$ in 1984:

$\frac{H_{m}}{H_{o}}=a\left[1-e^{\left(-b \Delta T^{c}\right)}\right]$

\section{Application of Artificial Neural Network}

Artificial neural networks have been used widely in many application areas. Most applications use a feed-forward neural network with the back-propagation training algorithm. There are numerous variants of the classical backpropagation algorithm and other training algorithms (Haykin, 1999). All these training algorithms assume a fixed ANN architecture and during training, they change the weights to obtain a satisfactory mapping of the data. The main advantage of the feed-forward neural networks is that they do not require a user-specified problem solving algorithm (as is the case with classic programming) but instead they "learn" from examples, much like human beings. Another advantage is that they possess inherent generalization ability. This means that they can identify and respond to patterns which are similar but not identical to the ones with which they have been trained. On the other hand, the development of a feed-forward ANN-model also poses certain problems, the most important being that there is no prior guarantee that the model will perform well for the problem at hand (Benghanem et al., 2009).

A feed-forward back-propagation neural network was used in this study. A typical neural network consists of an input, a hidden, and output layer. Other components include a neuron, weight, and connections or transfer function as shown in

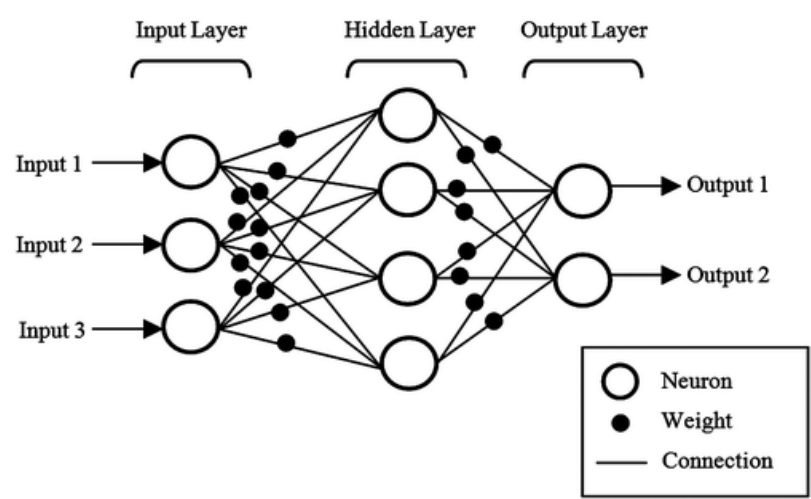

Fig. 1 and Fig. 2.

Fig. 1: A typical neural network for filtration

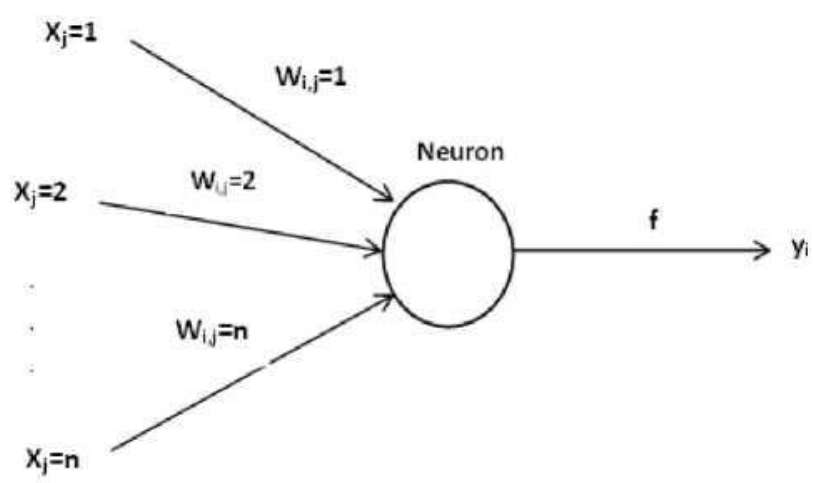

Fig. 2: Feed forward neural network

The values of $X_{1} ; X_{2}, X_{n}$ are inputs and $W i, W_{2}, W_{n}$ are weights. Each input is multiplied by the relevant weight. Obtaining products and bias are summarized. By applying activation function to the result of summary, the output of neuron is obtained. There are three steps in solving an ANN problem which are 1) training 2) generalization and 3) learning. Training is a process that network learns to recognize present pattern from input data set together with the desired pattern of activities for the output units. Generalization or testing evaluates network ability in order to extract a feasible solution when the inputs are unknown to network 
and are not trained to network. We determine how closely the actual output of the network matches the desired output in new situations. In the learning process the values of interconnection weights are adjusted so that the network produces a better approximation of the desired output. The disadvantage is that its operation can be unpredictable, because the network finds out by itself how to solve the problem.

The most common neural network model is the Multilayer Perceptron (Sharda and Patil, 1990). This type of neural network is known as a supervised network because it requires a desired output in order to learn. The goal of this type of network is to create a model that correctly maps the input to the output using historical data, so that the model can then be used to produce the output when the desired output is unknown.

Figure 1 shows the block diagram of a single hidden layer multiplayer perceptron (MLP). The inputs are fed into the input layer and get multiplied by interconnection weights as they are passed from the input layer to the hidden layer. Within the hidden layer, they get summed then processed by a nonlinear function (usually the hyperbolic tangent). If more than a single hidden layer exists then, as the processed data leaves the first hidden layer, again it gets multiplied by interconnection weights, then summed and processed by the second hidden layer and so on. Finally the data is multiplied by interconnection weights then processed one last time within the output layer to produce the neural network output. To perform any task, a set of experiments of an input output mapping is needed to train the neural network. These data are one of the most important factors to obtain reliable results from any trained ANN. Thus, the training sample data have to be fairly large to contain all the required information and must include a wide variety of data from different experimental conditions and process parameters.

In the present study, feed-forward, backpropagation, multilayer perceptron artificial neural network models are developed and trained separately by using Levenberg- Marquardt (LM) training algorithm and Gradient descent back propagation (GD) algorithm on 'Neural Network Toolbox' in MATLAB 9.7 version, to predict the average global solar radiation using meteorological data from 2014 - 2018 for Yola. The aim of this study is to investigate the feasibility of using ANN to model the non-linear relationship between solar radiation and other easily measurable important meteorological parameters. The predicted solar radiation values from the model can be used easily for design and assessment of renewable energy application systems.

\section{Design of the Artificial Neural Network Model}

Multi-layer feed-forward backpropagation network with different architecture were designed using the 'Neural Network Toolbox in MATLAB 9.7 version. The network consist of three layers: input layer, hidden layer and output layer. There are two input parameters for the models 1 and 2 and three input parameters for the model 3 and one output parameter average global solar radiation for all the three models. Two different algorithms (LM and GD method) with single and double hidden layer topologies were used and the number of neurons was also varied to enhance the generalization capability of the network. No transfer function was used for input layer, hyperbolic tangent sigmoid transfer function for hidden layer and linear transfer function (purelin) for output layer.

Selecting the number of neurons for the hidden layer is a complicated problem. So far, no mathematically justifiable method is available for 
determining the hidden elements. Too many network nodes will increase the training time of the network and weaken the generalization and forecasting ability of the network. The number of the hidden elements is obtained by trial and error. Training is started with a minimum number of elements, the number of these elements is constantly increased and re-training of the ANN is continued until satisfactory training is achieved. The number of the hidden elements used for satisfactory training is considered as the optimal number.

\section{Statistical Analysis}

The performance of the models was evaluated on the basis of the following statistical error tests: the mean percentage error (MPE), root mean square error (RMSE) and mean bias error (MBE). These tests are the ones that are applied most commonly in comparing the models of solar radiation estimations. It is recommended that a zero value for MBE is ideal while a low RMSE and low MPE are desirable (Igbal, 1983; Akpabio et al., 2004; Chen, 2011).

Mean percentage error: The Mean percentage error is defined as:

$\operatorname{MPE}(\%)=\frac{1}{n} \sum_{i=1}^{n}\left(\frac{\left(H_{i, m}-H_{i, c}\right)}{H_{i, m}}\right) \times 100$

Where $\mathrm{H}_{\mathrm{i}, \mathrm{m}}$ is the ith measured value, $\mathrm{H}_{\mathrm{i}, \mathrm{c}}$ is the ith calculated value of solar radiation and $\mathrm{N}$ is the total number of observations.

$R M S E=\left[\frac{1}{n} \sum_{i=1}^{n}\left(H_{i, m}-H_{i, c}\right)^{2}\right]^{\frac{1}{2}}$

$M B E=\frac{1}{n} \sum_{i=1}^{n}\left(H_{i, m}-H_{i, c}\right)$

According to Medugu and Yakubu (2011),

regression coefficient $a$ and $b$ from the calculated monthly average global solar radiation has been obtained from the relationship given as:

$$
\begin{aligned}
& a=-0.110+0.235 \cos \varphi+0.323\left(\frac{\mathrm{n}}{\mathrm{N}}\right) \\
& \mathrm{b}=1.449-0.553 \cos \varphi-0.694\left(\frac{\mathrm{n}}{\mathrm{N}}\right)
\end{aligned}
$$

To compute estimated values of the monthly average daily global radiation $H_{c a l}$, the values of computed $a$ and $b$ from equations (14) and (15) were used. where $\mathrm{a}=0.293$ and $\mathrm{b}=0.537$.

\section{RESULTS AND DISCUSSIONS}

Table 1 below gives the average computed values for the period of five years.

Table 1: Monthly Daily Average Meteorological data for Yola

\begin{tabular}{lllllcc}
\hline Months & $\begin{array}{l}\mathrm{RH} \\
(\%)\end{array}$ & $\begin{array}{l}\mathrm{RF} \\
(\mathrm{mm})\end{array}$ & $\begin{array}{l}\mathrm{T}_{\max } \\
\left({ }^{\circ} \mathrm{C}\right)\end{array}$ & $\begin{array}{l}\mathrm{T}_{\min } \\
\left({ }^{\circ} \mathrm{C}\right)\end{array}$ & $\frac{\mathrm{n}}{\mathrm{N}}$ & $\mathrm{H}_{\mathrm{m}}$ \\
\hline Jan. & 33.4 & 0.00 & 35.1 & 19.7 & 0.79 & 19.9 \\
Feb. & 30.2 & 0.00 & 39.6 & 22.2 & 0.64 & 21.3 \\
Mar. & 27.7 & 0.00 & 42.8 & 26.3 & 0.61 & 22.5 \\
Apri. & 49.5 & 44.9 & 38.9 & 29.5 & 0.65 & 20.4 \\
May & 68.7 & 98.7 & 34.6 & 27.1 & 0.52 & 19.7 \\
Jun. & 88.3 & 150.4 & 32.9 & 25.9 & 0.53 & 18.1 \\
Jul & 89.5 & 160.9 & 31.6 & 24.7 & 0.58 & 17.6 \\
Aug. & 96.2 & 203.2 & 32.3 & 24.3 & 0.44 & 15.8 \\
Sept. & 94.8 & 167.8 & 34.5 & 24.7 & 0.54 & 17.6 \\
Oct. & 78.5 & 87.4 & 35.8 & 24.5 & 0.68 & 20.3 \\
Nov. & 65.2 & 34.98 & 38.6 & 23.9 & 0.44 & 22.9 \\
Dec. & 53.5 & 0.00 & 36.5 & 21.8 & 0.53 & 18.4 \\
\hline
\end{tabular}

Table 2: Monthly average daily global solar radiation for Yola.

\begin{tabular}{lcccc}
\hline Months & $\frac{\mathrm{n}}{\mathrm{N}}$ & $\mathrm{H}_{\mathrm{m}}$ & $\mathrm{H}_{\mathrm{o}}$ & $\frac{\mathrm{H}_{\mathrm{m}}}{\mathrm{H}_{\mathrm{o}}}$ \\
\hline Jan. & 0.79 & 19.9 & 35.8 & 0.55 \\
Feb. & 0.64 & 21.3 & 37.7 & 0.56 \\
Mar. & 0.61 & 22.5 & 39.8 & 0.56 \\
Apri. & 0.65 & 20.4 & 40.9 & 0.49 \\
May & 0.52 & 19.7 & 39.3 & 0.50
\end{tabular}




\begin{tabular}{lllll}
\hline Jun. & 0.53 & 18.1 & 38.4 & 0.47 \\
Jul & 0.58 & 17.6 & 37.5 & 0.46 \\
Aug. & 0.44 & 15.8 & 36.3 & 0.43 \\
Sept. & 0.54 & 17.6 & 39.5 & 0.44 \\
Oct. & 0.68 & 20.3 & 38.2 & 0.53 \\
Nov. & 0.44 & 22.9 & 33.7 & 0.67 \\
Dec. & 0.53 & 18.4 & 32.5 & 0.56 \\
\hline
\end{tabular}

Figure 3: Relationship between the clearness index and relative sunshine duration in Yola.

Table 3: Monthly average daily global solar radiation for the three models and ANN

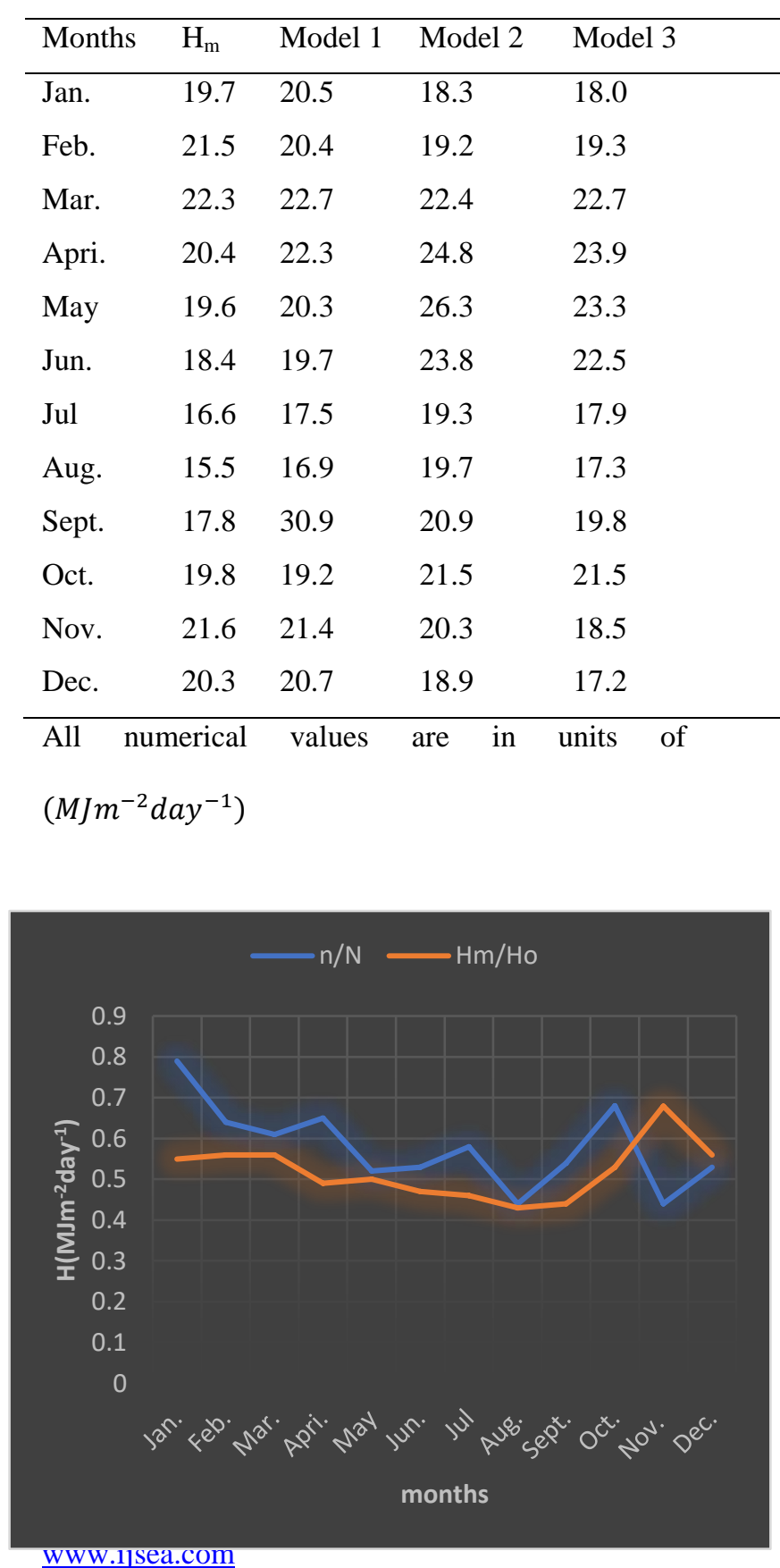

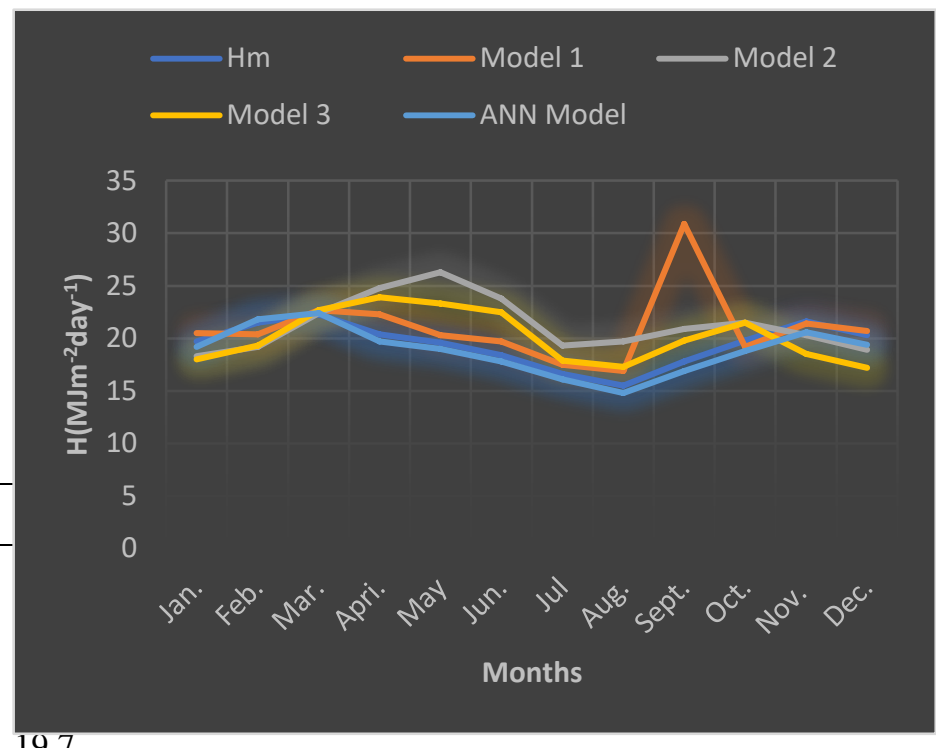

$$
19.7
$$

19.01

\section{8}

Figulre 4: Estimated value of monthly average daily 14.8global solar radiation and measured value 16.9

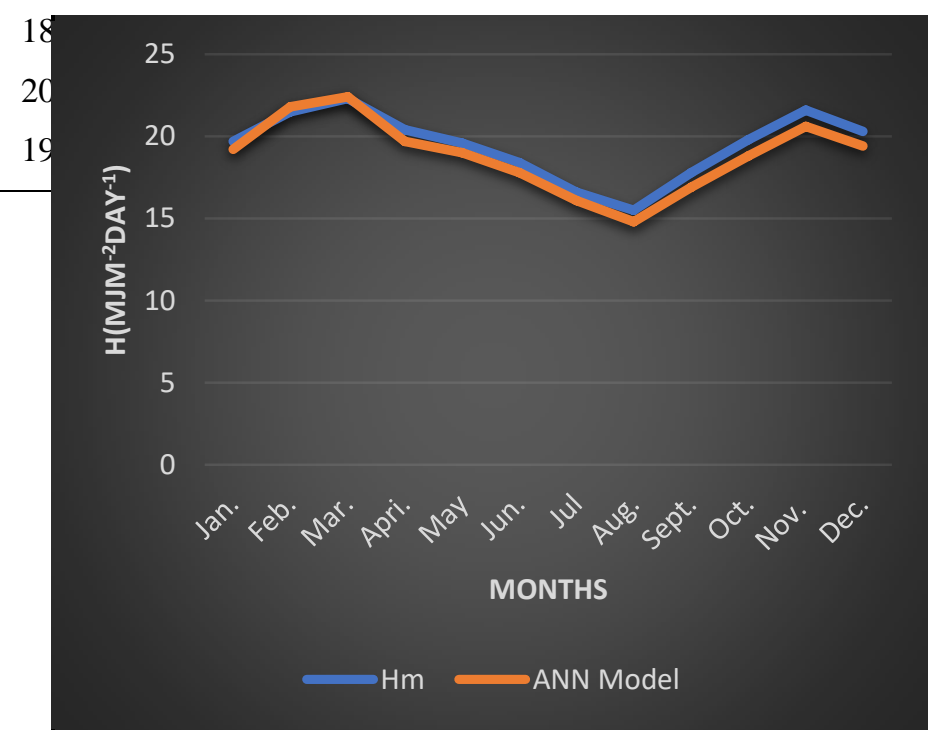

Figure 5: Estimated value of monthly average daily global solar radiation (Model 1) and measured values. 
Table 4: RMSE, $M B E$, and $M P E$ computed in the comparison between measured and estimated monthly average daily solar radiation

\begin{tabular}{llll}
\hline Models & \multicolumn{3}{c}{ Statistical Analysis Methods } \\
\hline & RMSE & MBE & MPE (\%) \\
\hline Model 1 & 6.72 & 0.42 & -1.194 \\
Model 2 & 10.39 & 2.39 & 0.378 \\
Model 3 & 9.83 & 1.76 & 2.256 \\
ANN Model & 4.74 & -1.029 & -2.345 \\
\hline
\end{tabular}

The best predicted versus measured irradiation values for ANN model was presented in Figure 5 and the values were presented in Table 3. In Table 2 and figure 3 , the value of clearness Index, $K_{T}=0.519$ correspond to the lowest value of $\frac{n}{N}=0.44$ and $\mathrm{H}_{\mathrm{m}}=15.8\left(\mathrm{MJm}^{-2} \mathrm{day}^{-1}\right)$ in the month of August indicate poor sky conditions. These conditions correspond to the wet or rainy season (June - September) observed in Yola during which is much cloud cover. The monthly average daily solar radiation estimated through model 1 and model 4 for Yola are given in Table 3, along with the measured values. It is very encouraging to observe a very fine agreement between the ANN and the measured values. Figure 2 indicates that ANN model is the most suitable for the estimation of monthly average daily global solar radiation for Yola. Shown in table 4 are the statistical test results. The RMSE values, which are is the measure of accuracy of a particular model or correlation use. For the present analysis, it was found to be lowest for ANN model value (4.74) as shown in table 4. The MBE values obtained from the models are positive in some cases and negative in others, which shows that these models vary between under and over estimate of global solar radiation. However, model has the lowest under estimation with a value of -1.029 , which is expected and acceptable. A low value of MPE is expected, ANN model was observed to have an MPE value of (-2.345).

The global solar radiation can be adequately estimated using different proposed models using daily recorded meteorological variables of maximum and minimum temperature difference, relative humidity, cloud cover and rainfall. In order to obtain some accurate solar radiation estimations, it requires accurate mathematical modelling of all the climatological parameters. From figure 3, there is high proportion of cloudy days, relative to low solar energy with low temperature in the wet season while low cloudy day with high solar energy and high temperature in dry season across the latitudes. It was observed that the ANN models which gives good results when considering statistical indicators, RMSE, MBE, and MPE. It is found that the new model can be used for estimating daily values of global solar radiation with a higher accuracy and has good adaptability to highly variable weather conditions. The estimated value of global solar radiation reveals that solar radiation can be efficiently used to compensate for energy inadequacy.

\section{CONCLUSION}

This study has been proposed the model of ANN to predict monthly average daily global solar irradiation in horizontal surface in Yola, Nigeria as area of study. This study proves that ANN can be used predicting of global solar irradiation potential in Yola, Nigeria by using meteorological data. In view of the worldwide concern about the economic importance of global solar radiation as an alternative renewable energy, the monthly global solar radiation using relative humidity, sunshine 
hour, cloud cover, rainfall, maxi maximum temperature have been employed in this study to estimate global solar radiation for Yola, Adamawa State, Nigeria. This model will provide useful information for designers and engineers of solar energy and other renewable energy devices in Yola and environs. From the results when considering statistical indicators that are MBE, RMSE and MPE. This study plan can be introduced neural network technique for modeling the global solar irradiation in Yola.

\section{REFERENCES}

Akpabio, L. E., Udo S. O. and Etuk S. E., (2004). Empirical correlation of globalsolar radiationwith Meteorological data for Orme, Nigeria. Turkish J. Physics, 28: 222-227

Allen, R.G., (1997). Self-calibrating method for estimating solar radiation from air temperature. ASCE J. Hydrol. Eng. 2, 56 57.

Angstrom, A., (1924). Solar and terrestrial radiation. Quart. Jour. Roy. Meteorol. Soc. 50, $\quad 121-125$.

Anstett M. and Kreider J. F. (1992), “Application of Neural Networking Models to predict energy use", ASHRAE Transactions, Paper No. 3672, pp. 505-517.

Benghanem M. Benghanem, A. Mellit and S.N. Alamri, (2009). ANN-based modelling and estimation of daily global solar radiation data: A case study, Energy Conversion

and Management, vol. 50, pp. 1644-1655.

Bristow K.L. and Campbell G.S. (1984). The relationship between incoming solar radiation and daily maximum and minimum temperature. Agricultural and Forest Meteorology. 31:159-166

Chen, C.J., (2011). Physics of Solar Energy, 10th edition, Department of Applied Physics and Applied Mathematics Columbia University: John Wiley \& Sons.

Cooper, P.I (1969). "The Absorption of Radiation on Solar Stills", Solar Energy, vol. 12, no. 3 , pp $333-346$.
Duffie, J. A. and Beckman, W. A., (1991). Solar Engineering of Thermal Processes, $2^{\text {nd }}$ edition, New York: Wiley.

Falayi, E.O., Rabiu, A.B. and Teliat, R.O., (2011). Correlation to estimate monthly mean of daily diffuse solar radiation in some selected cities in Nigeria. Pelagie Research Library, 2(4):480-490

Gana N.N, Jitendra K.R, and Musa M. (2014). Angstrom Constants for Estimatiing Solar Radiation in Sokoto, North Western, Nigeria, International journal of scientific \& Engineering Research, 5(1).

Hagan M.T, Demuth H.B., and Beale M.H.,

(1997), Neural Network Design. PWS Publishing Co: Boston, MA, USA.

Haykin S., (1999). Neural networks, a comprehensive foundation. New York, MacMillan, 1999.

Igbal, M., (1983). An Introduction to solar radiation. Academic press. New York. 5967

Kartini S., Sufiyan A.H., Jedol D., Mohamad

Z.H.M and Mohd S.S, (2015). Measurement of Global Solar Radiation in Kota Kinabalu Malasiya, ARPN Journal of Engineering and Applied Sciences, Vol.10, No.15.

Kreider J. F. and Wan X. A. (1991), “Artificial Neural Network demonstration for automated generation of energy use predictors for commercial buildings", ASHRAE Transactions, 97 (2), pp. 775779 .

Medugu, D.W. and Yakubu, D., (2011). Estimation of mean monthly global solar radiation in Yola- Nigeria using angstrom model; Advances in Applied Science Research, 2 (2): 414-421

Medugu D.W, Adisa A.B, Burari F.W, and Abdul Azeez M.A, (2013). Solar Radiation: correlation between measured and predicted values in Mubi, Nigeria, International Journal of Science and Technology Education Research, Vol 4(1), pp. 11-17.

Neuwirth, F., (1980). The estimation of global and sky radiation in Austria. Sol. Energy 24, $421-426$.

Okundamiya M.S. and Nzeako A.N., (2010). Empirical Model for Estimating Global Solar Radiation on Horizontal Surfaces for Selected Cities in the Six Geopolitical 
International Journal of Science and Engineering Applications

Volume 9 - Issue 07, 107 - 116, 2020, ISSN:- 2319 - 7560

Zones in Nigeria. Research Journal of Applied Sciences, Engineering and Technology. 2(8): 805-812.

Prescott, J.A., (1940). Evaporation from a water surface in relation to solar radiation.

Trans. R. Soc. Sci. Australia 64, 114 - 125.

Sharda R., and Patil R., (1990). "Neural Networks as forecasting experts: an empirical test," Proceedings of the 1990 Int. Joint Conf.
Neural Networks, I: 491-494, Washington DC, USA.

Stevenson W. J. (1994), “Using Artificial Neural Networks to predict building energy parameters", ASHRAE Transactions, 100 (2), Paper No. OR-94-17-4.

Yola Climate Report (2012). Retrieved March 12, 2012 from http://www.climatemps.com 